\title{
Scope and consistency of outcomes reported in randomized trials conducted in adults on hemodialysis: a systematic review
}

\section{Authors first and last names and highest degrees:}

Bénédicte Sautenet, M.D, Ph.D. ${ }^{1,2,3,4,5}$, Allison Tong, Ph.D ${ }^{1,2}$, Gabrielle Williams, Ph.D ${ }^{1,2}$, Brenda R Hemmelgarn, M.D, Ph.D ${ }^{6}$, Braden Manns, $\mathrm{MD}^{6}$, David C Wheeler, MD ${ }^{7}$, Peter Tugwell, M.D., Ph.D ${ }^{8}$, Wim van Biesen, M.D, Ph.D ${ }^{9}$, Wolfgang C Winkelmayer, M.D. ${ }^{10}$, Sally Crowe, PG.Dip. ${ }^{11}$, Tess Harris, patient advocate ${ }^{12}$, Nicole Evangelidis, B.Sc. ${ }^{1,2}$, Carmel M Hawley, MBBS ${ }^{13,14,15}$, Carol Pollock, M.D., Ph.D ${ }^{16}$, David W Johnson, M.D., PhD ${ }^{13,14,15}$, Kevan R Polkinghorne, M.D., $\mathrm{PhD}^{17,18}$, Kirsten Howard, $\mathrm{PhD}^{1}$, Martin P Gallagher, M.D., $\mathrm{PhD}^{19}$, Peter G Kerr, M.D., PhD ${ }^{17,18}$, Stephen P McDonald, M.D., PhD ${ }^{20,21}$, Angela Ju, BSc (Hons) ${ }^{1,2}$, Jonathan C Craig, MBChB, Ph.D. ${ }^{1,2}$

\section{Institution of each author:}

${ }^{1}$ Sydney School of Public Health, The University of Sydney, Sydney, Australia

${ }^{2}$ Centre for Kidney Research, The Children's Hospital at Westmead, Westmead, Sydney, Australia ${ }^{3}$ University Francois Rabelais, Tours, France

${ }^{4}$ Department of Nephrology and Clinical Immunology, Tours Hospital, Tours, France ${ }^{5}$ INSERM, U1246, Tours, France

${ }^{6}$ Departments of Medicine and Community Health Sciences; Libin Cardiovascular Institute and O'Brien Institute of Public Health, University of Calgary, Calgary, Canada

${ }^{7}$ Centre for Nephrology, University College London, London, United Kingdom

${ }^{8}$ Department of Medicine, University of Ottawa, Ottawa, Canada

${ }^{9}$ Renal Division, Ghent University Hospital, Ghent, Belgium

${ }^{10}$ Selzman Institute for Kidney Health, Section of Nephrology, Baylor College of Medicine, Houston, United States 
${ }^{11}$ Crowe Associates, Oxon, United Kingdom

${ }^{12}$ PKD International, Geneva, Switzerland

${ }^{13}$ Queensland School of Medicine, University of Queensland at Princess Alexandra Hospital,

Brisbane, Australia

${ }^{14}$ Translational Research Institute, Brisbane, Australia

${ }^{15}$ Metro South and Ipswich Nephrology and Transplant Services (MINTS), Brisbane, Australia

${ }^{16}$ Renal Division, Kolling Institute, Sydney, New South Wales, Australia

${ }^{17}$ Monash Medical Centre and Monash University, Clayton, Australia

${ }^{18}$ Department of Epidemiology \& Preventative Medicine, Monash University

${ }^{19}$ Concord Clinical School, The University of Sydney, Sydney, Australia

${ }^{20}$ Northern Adelaide Renal and Transplantation Service, Royal Adelaide Hospital, Adelaide, Australia

${ }^{21}$ Faculty of Health Science, University of Adelaide, Adelaide, Australia

\section{Corresponding author}

Bénédicte Sautenet

Department of Nephrology and Clinical Immunology

University Hospital Bretonneau

2 bd Tonnellé, 37000 Tours, France

Tel: $(+33) 689683866 \quad$ Fax: $(+33) 234378901$

Email: benedicte.sautenet@univ-tours.fr

Word count (abstract): 252

Word count (body): 3185

Short title: Outcomes reported in hemodialysis trials 


\begin{abstract}
Background: Clinical trials are most informative for evidence-based decision-making when they consistently measure and report outcomes of relevance to stakeholders. We aimed to assess the scope and consistency of outcomes reported in trials for hemodialysis.
\end{abstract}

Study Design: Systematic review.

Setting \& Population: Adults requiring maintenance hemodialysis.

Selection criteria: All Cochrane systematic reviews of interventions published by the $29^{\text {th }}$ of August 2016 and the trials published and registered in ClinicalTrial.gov since January 2011. Interventions: Any hemodialysis-related interventions.

Outcomes: Frequency and characteristics of the outcome domains and measures reported. Results: From the 362 included trials, we extracted and classified 10713 outcomes measures (median 21 per trial, interquartile range 10 to 39) into 81 different outcome domains, of which 42 $(52 \%)$ were surrogate, $25(31 \%)$ clinical and $14(17 \%)$, patient-reported. The number of outcomes measures reported significantly changed over time. The five most commonly reported domains were all surrogates: phosphate (125 [35\%] trials), dialysis adequacy (120 [33\%]), anemia (115 [32\%]), inflammatory markers (114 [31\%]) and calcium (109 [30\%]). Mortality, cardiovascular diseases and quality of life were reported very infrequently (73 [20\%], 44 [12\%] and 32 [9\%], respectively).

Limitations: For feasibility, we included a sampling frame of 362 trials.

Conclusions: The outcomes reported in clinical trials involving adults on hemodialysis are focused on surrogate outcomes, rather than on clinical and patient-centered outcomes. There is also extreme multiplicity and heterogeneity at every level - domain, measure, metric, and time point - making estimates of comparative effectiveness of available interventions unreliable and no improvements over time are evident.

Key words: Hemodialysis, systematic review, outcomes, patient-centered outcomes, nephrology Summary: What are the scope, quality and consistency of outcomes domains and measures in hemodialysis trials? Across 362 randomized controlled trials in adults on chronic hemodialysis, 81 
different outcomes domains and 10713 outcomes measures were reported. The outcomes were predominantly focused on surrogate endpoints, rather than on patient-centered outcomes limiting the ability of trials to inform shared decision making. This study provides an empiric evidence of the extreme multiplicity and heterogeneity of the outcomes used in hemodialysis trials at every level - domain, measurement, threshold and time point, which highlights an urgent need to standardize outcome reporting in trials. 


\section{Introduction}

Worldwide, an estimated US $\$ 240$ billion is invested annually into biomedical research and about half of this funding is from governmental or non-profit sources. ${ }^{1,2}$ It is estimated that $85 \%$ of the total investment is wasted due to problems with how research is prioritized, designed, reported and disseminated. ${ }^{1,3-7}$ A major cause of this postulated waste may be attributed to way that outcomes are measured and reported. Many outcomes reported may have limited clinical or policy relevance, important domains may not be reported, and different measures may have been used. Collectively, these problems may make reliable judgments about the relative effects of interventions difficult, and the clinical and policy relevance of published research findings substantially uncertain. ${ }^{8}$

The unreliability of trials introduced by the selective reporting of outcomes in favor of statistically significant outcomes (outcomes reporting bias), and the use of non-validated surrogates are well recognized. ${ }^{9}$ More recently, the more fundamental problem of prioritizing research questions based upon commercial or other considerations rather than the needs of patients, clinicians and regulators, and the focus on outcomes that may not be critically relevant to the end-users of research have also been highlighted. ${ }^{9-12}$ Despite these major concerns, detailed empiric evaluations of the scope and variability of outcomes in randomized trials and at every level - domain, measurement, threshold, and time point - are sparse.

Hemodialysis is one of the most costly interventions used in healthcare, and imposes an immense burden on healthcare systems and people. ${ }^{13-15}$ An estimated two million people with end-stage kidney disease depend on hemodialysis globally, who have a mortality rate of 27 per 100 patientyears in the four first months after dialysis initiation, which exceeds the general population by more than ten fold. ${ }^{16-19}$ Hemodialysis is also an invasive and demanding treatment that requires patients to be attached to a machine for ten to 30 hours per week, with devastating consequences on quality of life. ${ }^{20-23}$ Although the research investment in hemodialysis has been substantial, the translation into 
improvements in patient outcomes has been modest at best. ${ }^{24}$ The aims of this study were to describe the scope, quality and consistency of outcomes domains and measures in hemodialysis trials to inform strategies to improve outcome selection and reporting and thereby increase the value of future trials to inform clinical decisions.

\section{Methods}

\section{Selection criteria}

We searched the Cochrane Database of Systematic Reviews to identify all systematic reviews that included trials involving prevalent patients on chronic hemodialysis up to $29^{\text {th }}$ Aug 2016 without languages restriction. From each systematic review, we obtained the full text of randomized controlled trials (RCTs) from the list of included studies. To obtain a contemporary sample, we also searched ClinicalTrials.gov (from January 2011 to $29^{\text {th }}$ Aug 2016) for all published trials that enrolled prevalent patients on chronic hemodialysis and had analyzed published results from the trials. We excluded trials that did not include adults (defined as those 18 years of age or older).

\section{Data extraction}

For each trial, we extracted the following trial characteristics: first author, year of publication, participating countries, sample size, mean age of participants, study duration, intervention type, primary outcome, and, all outcomes/outcome measures. An outcome measure was defined as any measurement or event reported separately for all trial arms. All levels of specification of the outcome measures were extracted if reported: domain (e.g. kidney function), specific measurement (e.g. estimation of glomerular filtration rate by the modification of the diet in renal disease formula), method of aggregation (percentage change), specific metric (between the start and the end 
of the study period), ${ }^{25,26}$ and time frame in relation to the commencement of the trial and the measure of the outcome.

Analysis

The outcome measures from all included trials were grouped into outcome domains by two reviewers independently and discrepancies were discussed to reach agreement (BS, GW). The list of outcome domains was reviewed and agreed upon by four reviewers (AT, BS, GW, JCC). Reviewer BS grouped all outcome domains into three categories, surrogate (biochemical or physiological outcomes that may or may not be validated), clinical (medical outcomes based on clinician assessment or diagnosis), and patient-reported (outcomes reported by the patients usually relating to quality of life or symptoms), using standard definitions. ${ }^{27,28}$ The classification was agreed by two reviewers (AT, JCC). The number of trials that reported each outcome domain was then calculated. The primary outcome, if specified, was identified and we noted if multiple primary outcomes were reported in the same trial. For feasibility reasons, we were unable to evaluate the different outcome measures for all 81 outcome domains, but limited our detailed, measure-specific analysis to two selected frequently reported outcome domains in each category (six in total), including the measurement, aggregation, metric and timing reported. We performed three sensitivity analyses. We excluded trials of less than 3 months in duration, we excluded trials of less or equal to 20 patients then we excluded trials published after 2010. We compared the characteristics of the outcomes domains, primary outcomes, and outcomes measures by 5-year intervals (1977 to 2015) with binomial regression, analysis of variance, and Chi-square tests. We performed statistical analyses using R version 3.2.3 (R Foundation for Statistical Computing, Vienna, Austria, URL http://www.R-project.org/) to evaluate change over time. 
Role of the funding source: The funding source had no role in the study design, data collection, data analysis, data interpretation, or writing of the report. BS, AT, and JCC add full access to all the data and were responsible for the decision to submit for publication.

\section{Results}

\section{Trial characteristics}

We identified a total of 362 trials involving 42081 participants (Figure 1). The trial characteristics are provided in Table 1. The trials were conducted in 49 countries, including the United States (90 [25\%] trials), Italy (31 [9\%]), Germany (21 [6\%], Canada 18 [5\%]), Japan (17 [5\%]). Twenty (6\%) trials involved sites in more than one country. The year of trial publication ranged from 1977 to 2015, the median (interquartile range [IQR]) duration of trials was 6 months (3 to 12 months) and the median (IQR) sample size was 42 patients (23 to 85 patients).

\section{Outcome measures and domains}

In total, 10,713 outcome measures were reported across 362 trials. The number of outcome measures (inclusive of time points) ranged from 1 to 196 , with a median of 21 per trial (IQR 10 to 39 outcomes) (the same outcome measure with 2 time points different were counted as two different measures, e.g. mean serum calcium at 6 months and mean serum calcium at 12 months). The number of unique outcome measures (exclusive of time points) ranged from 1 to 63 , with a median of 9 per trial (IQR 5 to 16). Sixty-seven outcome measures were excluded as they were not considered relevant to prevalent patients on hemodialysis (e.g. "number starting dialysis") or were specific to a single intervention within the trial (e.g. "abrasion from ergometer", "change from anergic to reactive”). The remaining 10646 were classified into 81 outcome domains; which were 
grouped into three categories: surrogate (42 [51\%]), clinical $(25[31 \%])$ and patient-reported outcomes $(14[17 \%])$.

The proportion of trials reporting each outcome domain is provided in Figure 2. The five most commonly reported domains were all surrogates: phosphate (125 [35\%] trials), dialysis adequacy (120 [33\%]), anemia (115 [32\%]), inflammatory markers/oxidative stress (114 [31\%]) and calcium (109 [30\%]). Mortality and cardiovascular disease were reported in $73(20 \%)$ and $44(12 \%)$ of trials, respectively. Quality of life and fatigue/energy were reported in $32(9 \%)$ and $35(10 \%)$ of trials, respectively.

The number of trials reporting at least one surrogate outcome domain was $322(89 \%), 211$ (58\%) trials reported at least one clinical outcome domain, and $128(35 \%)$ trials reported at least one patient-reported outcome. Of the $26(32 \%)$ outcomes reported by at least $10 \%$ of trials, $18(22 \%)$ were surrogate, $6(7 \%)$ clinical and $2(3 \%)$ patient-reported.

Forty nine $(60 \%)$ outcome domains had more than 10 different outcome measures (exclusive of time point). The range of specific outcome measures for six outcome domains (two selected outcome domains for surrogate, clinical and patient-reported outcomes) and the time points of measurement are provided in Figures $3 \mathrm{a}-3 \mathrm{f}$. For the category surrogate outcome we assessed "serum phosphate" and "serum calcium", with 35 (254 including different time points) and 35 (258 including time points) different measures used across all trials, respectively (Figure 3a, 3b). For clinical outcomes, "mortality" and "cardiovascular diseases" had 48 (123 including time points) and 47 (109 including time points) different outcome measures, respectively (Figure 3c, 3d). The patient-reported outcomes of "pain" and "fatigue/energy" had 40 (81 including time points) and 18 (47 including time points) measures, respectively (Figure 3e, 3f). 
Across the 362 trials, 230 (64\%) did not specify the primary outcome, 40 (11\%) specified several primary outcomes, and $92(26 \%)$ specified one unique primary outcome. The outcomes specified as primary outcomes corresponded to 35 different outcome domains: 19 (54\%) were surrogate outcomes, 10 (29\%) were clinical outcomes and 6 (17\%) were patient-reported outcomes. The 6 most frequently reported primary outcomes were vascular access (35 [27\%] trials), mortality (20 [15\%] trials), parathyroid hormone (15 [11\%] trials), cardiac function (12 [9\%] trials), anemia/hemoglobin/iron (8 [6\%] trials) and inflammatory markers/oxidative stress (8 [6\%] trials). The proportion of trials reporting each primary outcome domains is provided in the supplementary file, Table S1.

Comparison of outcomes characteristic over time

The number of outcomes reported significantly changed over time $(\mathrm{p}<0.001)$ and appeared to increase especially over the past ten years (Supplementary file - Figure S1). The proportion of trials that reported at least one clinical outcome significantly changed over time $(p<0.001)$ but the proportion of trials that reported at least one surrogate and one patient-reported outcome was stable ( $p=0.13$ and $p=0.66$, respectively) (Figure 4 ). The proportion of trials that specified a primary outcome significantly changed over time $(\mathrm{p}<0.001)$. The type of outcome (clinical, patient-reported or surrogate) did not change over time $(\mathrm{p}=0.07)$, however there was an increase in the reporting of clinical outcomes from 1991 to 2005 (Figure 5). The number of unique measures for each of the six selected clinical, surrogate and patient-reported outcomes continued to expand significantly over the study period (Table 2).

\section{Sensitivity analysis}


We performed a sensitivity analysis and excluded trials of less than 3 months in duration (69 trials). Across the 293 remaining trials, 9139 outcome measures were reported, which were classified into 81 outcome domains; and grouped into three categories: surrogate (42 [51\%]), clinical (25 [31\%]) and patient-reported outcomes (14 [17\%]). We performed a second sensitivity analysis and excluded trials of less or equal to 20 patients ( 79 trials). Across the 283 remaining trials, 8241 outcome measures were reported, which were classified into 80 outcome domains; and grouped into three categories: surrogate (42[53\%]), clinical $(24$ [30\%]) and patient-reported outcomes $(14[17 \%])$. We performed a third sensitivity analysis and excluded trials published after 2010 (81 trials). Across the 281 remaining trials, 8089 outcome measures were reported, which were classified into 81 outcome domains; and grouped into three categories: surrogate (42 [51\%]), clinical (25 [31\%]) and patient-reported outcomes (14 [17\%]). Compared with all trials, the proportion of trials that reported each outcome domain was similar for trials of 3 months or more duration, trials of more than 20 patients and trials published prior to 2011 (Supplementary File Table S2).

\section{Discussion}

The outcome domains reported in clinical trials involving adults on hemodialysis are heavily focused on surrogate outcomes, rather than on clinical and patient-centered outcomes like mortality, cardiovascular disease, and quality of life, so that the importance of the clinical trials results to clinical practice and policy are substantially uncertain. Moreover, the outcomes are extremely numerous and heterogeneous across trials at every level - domain, measurement, method of aggregation, metric and time point - making it very difficult to evaluate the comparative effectiveness of interventions. 
Three major issues regarding the reporting of outcomes in this setting have been identified. First, the outcomes reported lack clinical and policy relevance. Second, outcomes of clear relevance are seldom reported, and third, extreme heterogeneity and multiplicity of outcomes is evident, so that comparability of interventions is difficult to ascertain and outcomes reporting bias is made more likely.

Over $80 \%$ of outcome measures were biomarkers with serum phosphate, dialysis adequacy, anemia/hemoglobin/iron, inflammatory markers/oxidative stress and calcium as the top five most frequently reported outcome domains. However, hemodialysis is notable as it lacks a validated biomarker. Changes in serum phosphate, serum calcium, parathyroid hormone, and hemoglobin have not been shown to predict changes in mortality and cardiovascular events in randomized trials in patients on hemodialysis. ${ }^{29,30}$ The clinical relevance of trials that report these outcomes therefore remain uncertain at best, even if results of interventions were favorable. ${ }^{31-35}$ This may be even more important if patient-important outcomes such as functional, social and emotional well-being, either directly or indirectly affected by the intervention are not reported. ${ }^{4,11,36}$ We suggest that further research is needed to strengthen the causal link between surrogates and clinical outcomes so that they can be used to improve trial efficiency.

Conversely, most trials did not report outcomes that most would regard as important and highly relevant outcomes to patients on hemodialysis and their clinicians. Quality of life was reported in just $32(9 \%)$ trials, with mortality and cardiovascular endpoints being reported in only $73(20 \%)$ and $44(12 \%)$ trials, respectively. ${ }^{31}$ Studies across medical specialties, including nephrology, have consistently shown that patient-important outcomes in trials are uncommon. For example, only 93 (23\%) of 413 trials in cardiovascular disease and 78 (18\%) of 436 trials in diabetes included patientcentered outcomes. ${ }^{10,11}$ In nephrology, of the 66 systematic reviews focused on the prevention of progression to end-stage kidney disease, five $(8 \%)$ reviews assessed the quality of life. ${ }^{12}$ The priorities of patients with end-stage kidney disease include quality of life, anxiety, and fatigue but 
these outcomes were rarely evaluated in hemodialysis trials. ${ }^{37,38}$ The omission of patient-centered outcomes undermines the ability of the study to inform shared decision making in the context of effective treatments and care that takes into account the patient's priorities and values. Despite the increasing interest in using patient-reported outcomes measures in clinical trials, it remains a challenge ${ }^{39}$ Compared with surrogate endpoints, clinical outcomes and patient-reported outcomes may be more challenging to include in trials as they would generally require more time and resources, and a larger sample size. Specific challenges for patient-reported outcomes include the lack of well-validated measures for use in the CKD population, and uncertainty about what outcomes and outcome measures to use. ${ }^{40,41}$ Establishing core outcome domains that are important to patients and health professionals, and identifying or developing validated and feasible measures for use in trials may help to address these challenges. ${ }^{42}$

There is a need to identify the outcomes that are important to patients, then establish standardized, well-defined, responsive, and psychometrically robust patient-reported outcome measures for outcome domains that are relevant to patients. ${ }^{39}$ It has been recommended that specific patientreported outcome measures should at least focus on 'core, disease-related symptoms or on the functional effects of a disease, which may be affected by the intervention' ${ }^{43}$ These finding may reflect that important outcomes are not being measured or an outcome reporting bias whereby only outcomes in favor of the intervention are being reported. ${ }^{44,45}$

Our findings highlight the extreme multiplicity and heterogeneity in the outcome domains and measures across trials in hemodialysis with 81 different outcome domains and 10713 outcome measures reported. For example, serum phosphate (the most frequently reported outcome) was measured in 125 (35\% of trials, yet had 35 different outcomes measures. The differences in nomenclature, thresholds, and terms used for the same outcome can preclude comprehensive and systematic assessments of the comparative effect of interventions. Some of the differences in outcomes may be due to changes in interventions and understanding of methodology that have evolved over time. We speculate that such heterogeneity is not limited to hemodialysis but would be 
found in other medical specialties. However we are not aware of other studies that have systematically assessed the reporting of all outcome domains and at the level of outcome measures inclusive of definition, threshold, time points. ${ }^{46-48}$

Our study addresses an evidence gap by providing a detailed analysis of the scope and consistency of outcome domains, down to the level of outcome measures, across a large selection of hemodialysis trials. However, we acknowledge some potential limitations. As it was not feasible to include all trials in hemodialysis, Cochrane systematic reviews and ClinicalTrials.gov were used as a sampling frame, potentially introducing selection bias. As we did not include all trials, and because trials in Cochrane reviews would be similar in addressing the same topic, we expect that our results may underestimate the scope, inconsistency, and variability of outcome reporting. The older studies included were from Cochrane systematic reviews and any trends may be confounded with these sources, and given the smaller number of older trials, the estimates may be less reliable. Cochrane systematic reviews of RCTs probably cover most of the major topics and probably include most of the prominent and "landmark" RCTs in nephrology. 49

This work provides empiric evidence for the need to standardize outcome reporting in trials. Major initiatives have been forged to establish a consensus-based standardized set of core outcomes. A core outcome set is an 'agreed minimum set of outcomes to be measured and reported in all clinical trials of a specific disease or trial population, to ensure that the results of studies can be compared, contrasted and combined as appropriate, and to ensure all trials contribute relevant and usable information'. ${ }^{42,50,51}$ However, researchers can add other relevant outcomes, for example, outcomes that may be disease or condition specific. The Outcome Measures in Rheumatology (OMERACT), established in 1992, is the pioneering initiative for developing core outcomes, which has improved the consistency and reporting of outcomes in rheumatology trials. ${ }^{26,52,53}$ The World Health Organization (WHO) and the US Food and Drug Administration support the validity of OMERACT methodology for developing core outcomes. ${ }^{54}$ Now, there are more than 720 references of core 
outcome projects that span hundreds of disease areas registered in the Core Outcome Measures in Effectiveness Trials (COMET) database. A core outcome set is to be used as a minimum in trials for a given health condition because they are critically important to patients and health professionals. ${ }^{42}$ To complete a core outcome domain, establishing standardized outcome measures to enable the measurement and reporting of core outcome domains to inform shared decision-making among patients and their clinicians is needed. ${ }^{55}$ Further research may also be conducted to ascertain the perspectives of funding agencies and industry on implementing core outcomes in trials, to inform strategies for ensuring the important outcomes are reported in trials.

A wide array of outcomes is reported in trials of interventions in hemodialysis and most are biochemical endpoints. There is considerable multiplicity and heterogeneity in the outcomes chosen by clinical triallists to be measured and reported, from domain, through to measurement, method of aggregation, metric and timing across trials. The development of a core outcome set for hemodialysis trials that is based on the priorities of patients, caregivers and health professionals is needed and now underway via the Standardized Outcomes in Nephrology (SONG) initiative. ${ }^{56}$ The core outcome set proposed by the SONG-HD initiative ${ }^{57}$, is aimed to be relevant and feasible for pragmatic trials. Investigators would be expected to add other outcomes based on the type of trial (e.g. pilot versus a larger definitive trial), population, and scientific rationale of the intervention. This initiative is hoped to lead to better outcome reporting and to increase the value of trials for treatment decision-making ultimately leading to improvements for patients in outcomes important and relevant to them. 


\section{Declaration of interests}

BS, AT, GW, BM, BH, DCW, PT, WVB, WCW, SC, TH, NE, CMH, CP, DWJ, KRP, KH, MPG, PGK, SPD, AJ, JCC declare no competing interests.

\section{Contributions}

Research ideas and study design: BS, AT, GW, and JC; data acquisition: BS, GW; data analysis and interpretation: BS, AT, GW, and JC. Each author contributed important intellectual content during manuscript drafting or revision and accepts accountability for the overall work by ensuring that questions pertaining to the accuracy or integrity of any portion of the work are appropriately investigated and resolved.

\section{Support and financial disclosure declaration}

The project is funded by a National Health and Medical Research Council Project Grant (ID1098815). AT is supported by a National Health and Medical Research Council Fellowship (ID 1106716). BS is supported by a scholarship from the French Society of Hypertension and from the Hopitaux Universitaires Grand Ouest. The funding organizations had no role in the design and conduct of the study; collection, management, analysis and interpretation of the data; preparation, review, or approval of the manuscript. 


\section{References}

1. Macleod MR, Michie S, Roberts I, et al. Biomedical research: increasing value, reducing waste. Lancet. 2014;383(9912):101-4.

2. Dorsey ER, de Roulet J, Thompson JP, et al. Funding of US biomedical research, 2003-2008. JAMA. 2010;303(2):137-43.

3. Chalmers I, Glasziou P. Avoidable waste in the production and reporting of research evidence. Lancet. 2009;374(9683):86-9.

4. Chalmers I, Bracken MB, Djulbegovic B, et al. How to increase value and reduce waste when research priorities are set. Lancet. 2014;383(9912):156-65.

5. Chan A-W, Song F, Vickers A, et al. Increasing value and reducing waste: addressing inaccessible research. Lancet. 2014;383(9913):257-66.

6. Ioannidis JPA, Greenland S, Hlatky MA, et al. Increasing value and reducing waste in research design, conduct, and analysis. Lancet. 2014;383(9912):166-75.

7. Salman RA-S, Beller E, Kagan J, et al. Increasing value and reducing waste in biomedical research regulation and management. Lancet. 2014;383(9912):176-85.

8. Glasziou P, Altman DG, Bossuyt P, et al. Reducing waste from incomplete or unusable reports of biomedical research. Lancet. 2014;383(9913):267-76.

9. Fleming TR, Powers JH. Biomarkers and surrogate endpoints in clinical trials. Stat Med. 2012;31(25):2973-84.

10. Rahimi K, Malhotra A, Banning AP, Jenkinson C. Outcome selection and role of patient reported outcomes in contemporary cardiovascular trials: systematic review. $B M J$. 2010;341:c5707. 
11. Gandhi GY, Murad MH, Fujiyoshi A, et al. Patient-important outcomes in registered diabetes trials. JAMA. 2008;299(21):2543-9.

12. Sautenet B, Contentin L, Bigot A, Giraudeau B. Strong heterogeneity of outcome reporting in systematic reviews. J Clin Epidemiol. 2016;75:93-9.

13. Karopadi AN, Mason G, Rettore E, Ronco C. The role of economies of scale in the cost of dialysis across the world: a macroeconomic perspective. Nephrol Dial Transplant. 2014;29(4):885-92.

14. Klarenbach SW, Tonelli M, Chui B, Manns BJ. Economic evaluation of dialysis therapies. Nat Rev Nephrol. 2014;10(11):644-52.

15. Pai AB, Cardone KE, Manley HJ, et al. Medication reconciliation and therapy management in dialysis-dependent patients: need for a systematic approach. Clin J Am Soc Nephrol. 2013;8(11):1988-99.

16. Cheung AK, Sarnak MJ, Yan G, et al. Cardiac diseases in maintenance hemodialysis patients: results of the HEMO Study. Kidney Int. 2004;65(6):2380-9.

17. Go AS, Chertow GM, Fan D, McCulloch CE, Hsu C. Chronic kidney disease and the risks of death, cardiovascular events, and hospitalization. N Engl J Med. 2004;351(13):1296-305.

18. Robinson BM, Zhang J, Morgenstern H, et al. Worldwide, mortality risk is high soon after initiation of hemodialysis. Kidney Int. 2014;85(1):158-65.

19. Thomas B, Wulf S, Bikbov B, et al. Maintenance Dialysis throughout the World in Years 1990 and 2010. J Am Soc Nephrol. 2015;26(11):2621-33.

20. Cantekin I, Kavurmacı M, Tan M. An analysis of caregiver burden of patients with hemodialysis and peritoneal dialysis. Hemodial Int. 2016;20(1): 94-7. 
21. Karamanidou C, Weinman J, Horne R. A qualitative study of treatment burden among haemodialysis recipients. J Health Psychol. 2014;19(4):556-69.

22. Jhamb M, Tamura MK, Gassman J, et al. Design and Rationale of Health-Related Quality of Life and Patient-Reported Outcomes Assessment in the Frequent Hemodialysis Network Trials. Blood Purif. 2011;31(1-3):151-8.

23. Birmelé B, Le Gall A, Sautenet B, Aguerre C, Camus V. Clinical, sociodemographic, and psychological correlates of health-related quality of life in chronic hemodialysis patients. Psychosomatics. 2012;53(1):30-7.

24. Nissenson AR. Improving outcomes for ESRD patients: shifting the quality paradigm. Clin $J$ Am SocNephrol. 2014;9(2):430-4.

25. Zarin DA, Tse T, Williams RJ, Califf RM, Ide NC. The ClinicalTrials.gov results database-update and key issues. N Engl J Med. 2011;364(9):852-60.

26. Sautenet B, Caille A, Halimi J-M, Goupille P, Giraudeau B. Better reporting and greater homogeneity in outcome measures are seen in randomized trial protocols when guidelines exist. J Clin Epidemiol. 2013;66(8):838-46.

27. Black N. Patient reported outcome measures could help transform healthcare. $B M J$. 2013;346:f167.

28. Fleming TR, DeMets DL. Surrogate end points in clinical trials: are we being misled? Ann Intern Med. 1996;125(7):605-13.

29. Palmer SC, Hayen A, Macaskill P, et al. Serum levels of phosphorus, parathyroid hormone, and calcium and risks of death and cardiovascular disease in individuals with chronic kidney disease: a systematic review and meta-analysis. JAMA. 2011;305(11):1119-27. 
30. Palmer SC, Teixeira-Pinto A, Saglimbene V, et al. Association of Drug Effects on Serum Parathyroid Hormone, Phosphorus, and Calcium Levels With Mortality in CKD: A Metaanalysis. Am J Kidney Dis. 2015;66(6):962-71.

31. Urquhart-Secord R, Craig JC, Hemmelgarn B, et al. Patient and Caregiver Priorities for Outcomes in Hemodialysis: An International Nominal Group Technique Study. Am J Kidney Dis. 2016 Sep;68(3):444-54.

32. Perkovic V, Neal B. Trials in kidney disease--time to EVOLVE. $N$ Engl J Med. 2012;367(26):2541-2.

33. EVOLVE Trial Investigators, Chertow GM, Block GA, et al. Effect of cinacalcet on cardiovascular disease in patients undergoing dialysis. N Engl J Med. 2012;367(26):2482-94.

34. Fleming TR, DeMets DL. Surrogate end points in clinical trials: are we being misled? Ann Intern Med. 1996;125(7):605-13.

35. Halimi J-M, Sautenet B, Gatault P, Roland M, Giraudeau B. Renal endpoints in renal and cardiovascular randomized clinical trials: time for a consensus? Fundam Clin Pharmacol. 2012;26(6):771-82.

36. Ioannidis JPA, Horbar JD, Ovelman CM, et al. Completeness of main outcomes across randomized trials in entire discipline: survey of chronic lung disease outcomes in preterm infants. BMJ. 2015;350:h72.

37. Tong A, Crowe S, Chando S, et al. Research Priorities in CKD: Report of a National Workshop Conducted in Australia. Am J Kidney Dis. 2015;66(2):212-22.

38. Manns B, Hemmelgarn B, Lillie E, et al. Setting research priorities for patients on or nearing dialysis. Clin J Am Soc Nephrol. 2014;9(10):1813-21. 
39. Breckenridge K, Bekker HL, Gibbons E, et al. How to routinely collect data on patient-reported outcome and experience measures in renal registries in Europe: an expert consensus meeting. Nephrol Dial Transplant. 2015;30(10):1605-14.

40. Ju A, Unruh M, Davison S, et al. Patient-reported outcome measures for fatigue in patients on hemodialysis: a systematic review. Am J Kidney Dis. (Accepted 18th September 2017).

41. Tong A, Winkelmayer WC, Wheeler DC, et al. Nephrologists' perspectives on defining and applying patient-centered outcomes in hemodialysis. Clin J Am Soc Nephrol. 2017; 12(3):454466.

42. Williamson PR, Altman DG, Blazeby JM, et al. Developing core outcome sets for clinical trials: issues to consider. Trials. 2012;13:132.

43. Selewski DT, Thompson A, Kovacs S, et al. Patient-reported outcomes in glomerular disease. Clin J Am Soc Nephrol. 2016;12(1):140-148.

44. Pocock SJ, Stone GW. The Primary Outcome Fails — What Next? N Engl J Med. 2016;375(9):861-70.

45. Howell M, Wong G, Turner RM, et al. The Consistency and Reporting of Quality-of-Life Outcomes in Trials of Immunosuppressive Agents in Kidney Transplantation: A Systematic Review and Meta-analysis. Am J Kidney Dis. 2016;67(5):762-74.

46. Tendal B, Nüesch E, Higgins JPT, Jüni P, Gøtzsche PC. Multiplicity of data in trial reports and the reliability of meta-analyses: empirical study. BMJ. 2011;343:d4829.

47. Blencowe NS, Strong S, McNair AGK, et al. Reporting of short-term clinical outcomes after esophagectomy: a systematic review. Ann Surg. 2012;255(4):658-66.

48. Whitehead L, Perkins GD, Clarey A, Haywood KL. A systematic review of the outcomes reported in cardiac arrest clinical trials: the need for a core outcome set. Resuscitation. 2015;88:150-7. 
49. Palmer SC, Craig JC, Jones A, Higgins G, Willis N, Strippoli GF. Celebrating 20 years of evidence from the Cochrane Collaboration: what has been the impact of systematic reviews on nephrology? Nephrol Dial Transplant. 2015;30(6):871-77.

50. Kirkham JJ, Gargon E, Clarke M, Williamson PR. Can a core outcome set improve the quality of systematic reviews?--a survey of the Co-ordinating Editors of Cochrane Review Groups. Trials. 2013;14:21.

51. Gargon E, Gurung B, Medley N, et al. Choosing important health outcomes for comparative effectiveness research: a systematic review. PLoS One 2014; 9(6): e99111.

52. Singh JA, Solomon DH, Dougados M, et al. Contributions of OMERACT to rheumatic disease research. Arthritis Rheum. 2007;57(1):186.

53. Kirkham JJ, Boers M, Tugwell P, Clarke M, Williamson PR. Outcome measures in rheumatoid arthritis randomised trials over the last 50 years. Trials. 2013;14:324.

52. Tugwell P, Boers M, Brooks P, Simon L, Strand V, Idzerda L. OMERACT: an international initiative to improve outcome measurement in rheumatology. Trials. 2007;8:38.

54. Saldanha IJ, Li T, Yang C, et al. Social network analysis identified central outcomes for core outcome sets using systematic reviews of HIV/AIDS. J Clin Epidemiol. 2016;70:164-75

55. Williamson PR, Altman DG, Bagley H et al. The COMET Hanbook: version 1.0. Trials. 2017; 18(Suppl 3):280.

56. Tong A, Manns B, Hemmelgarn B, et al. Standardised outcomes in nephrology Haemodialysis (SONG-HD): study protocol for establishing a core outcome set in haemodialysis. Trials. 2015;16:364.

57. SONG Initiative. SONG-HD available at http://songinitiative.org/about-us/song-hd/ (Accessed 29th August 2016) 
Table 1. Characteristics of included trials $(n=362)$

\begin{tabular}{|c|c|}
\hline Trial characteristic & Number of trials $\mathrm{n}(\%)$ \\
\hline \multicolumn{2}{|l|}{ Year of publication } \\
\hline $1977-1979$ & $3(0.8)$ \\
\hline 1980-1989 & $22(6.1)$ \\
\hline 1990-1999 & $89(24.6)$ \\
\hline 2000-2009 & $158(43.6)$ \\
\hline $2010-2015$ & $90(24.9)$ \\
\hline \multicolumn{2}{|l|}{ Country } \\
\hline United States & $90(24.9)$ \\
\hline Italy & $31(8.6)$ \\
\hline Germany & $21(5.8)$ \\
\hline Canada & $18(5.0)$ \\
\hline Japan & $17(4.7)$ \\
\hline Greece & $16(4.4)$ \\
\hline United Kingdom & $15(4.1)$ \\
\hline Australia & $11(3.0)$ \\
\hline Netherlands & $11(3.0)$ \\
\hline Other & $112(30.9)$ \\
\hline Multinational studies & $20(5.5)$ \\
\hline \multicolumn{2}{|l|}{ Sample size } \\
\hline 1 to 50 & $211(58.3)$ \\
\hline 51 to 100 & $66(18.2)$ \\
\hline 101 to 150 & $29(8.0)$ \\
\hline 151 to 200 & $18(5.0)$ \\
\hline$>200$ & $35(9.7)$ \\
\hline Not reported & $3(0.8)$ \\
\hline \multicolumn{2}{|l|}{ Duration of trial (months) } \\
\hline$\leq 3$ & $122(33.7)$ \\
\hline$>3-6$ & $89(24.6)$ \\
\hline$>6-9$ & $26(7.2)$ \\
\hline$>9-12$ & $63(17.4)$ \\
\hline$>12$ & $57(15.7)$ \\
\hline Not reported & $5(1.4)$ \\
\hline \multicolumn{2}{|l|}{ Intervention type } \\
\hline Pharmacological & $161(44.5)$ \\
\hline Dialysis techniques & $115(31.8)$ \\
\hline Exercise & $40(11.0)$ \\
\hline Vascular access care & $43(11.9)$ \\
\hline Psychological & $3(0.3)$ \\
\hline \multicolumn{2}{|c|}{ Number of unique outcome measures reported in each trial } \\
\hline 0 to 10 & $213(58.8)$ \\
\hline 11 to 25 & $118(32 \cdot 6)$ \\
\hline 26 to 50 & $26(7.1)$ \\
\hline$>50$ & $5(1.4)^{*}$ \\
\hline
\end{tabular}

*the references of the 5 trials with more than 50 unique outcomes measures are specified in the Supplementary file) 
Table 2. Number of new measures reported in trials published over 5-year periods for six selected clinical, surrogate and patient reported domains

\begin{tabular}{|c|c|c|c|c|c|c|c|c|c|c|}
\hline \multirow[b]{2}{*}{ Outcome domain } & \multirow[b]{2}{*}{$\begin{array}{l}\text { Total } \\
\text { number of } \\
\text { measures }\end{array}$} & \multicolumn{8}{|c|}{ Number of new measures by time period (years) } & \multirow[b]{2}{*}{$\begin{array}{l}p \text {-value for } \\
\text { change } \\
\text { over time }\end{array}$} \\
\hline & & $\begin{array}{l}1977 \\
\text { to } \\
1980 \\
\end{array}$ & $\begin{array}{l}1981 \\
\text { to } \\
1985 \\
\end{array}$ & $\begin{array}{l}1986 \\
\text { to } \\
1990 \\
\end{array}$ & $\begin{array}{l}1991 \\
\text { to } \\
1995 \\
\end{array}$ & $\begin{array}{l}1996 \\
\text { to } \\
2000\end{array}$ & $\begin{array}{l}2001 \\
\text { to } \\
2005\end{array}$ & $\begin{array}{l}2006 \\
\text { to } \\
2010\end{array}$ & $\begin{array}{l}2011 \\
\text { to } \\
2015 \\
\end{array}$ & \\
\hline Mortality & 48 & 0 & 0 & 0 & 1 & 5 & 14 & 18 & 37 & $\mathrm{p}<0.001$ \\
\hline Cardiovascular disease & 47 & 0 & 1 & 1 & 5 & 10 & 24 & 11 & 30 & $\mathrm{p}<0.001$ \\
\hline Pain & 40 & 1 & 0 & 3 & 9 & 7 & 19 & 5 & 16 & $\mathrm{p}<0.001$ \\
\hline Fatigue/energy & 18 & 0 & 0 & 0 & 3 & 4 & 9 & 7 & 7 & $\mathrm{p}=0.01$ \\
\hline Phosphate & 35 & 1 & 2 & 3 & 9 & 12 & 16 & 5 & 13 & $\mathrm{p}=0.01$ \\
\hline Calcium & 35 & 4 & 3 & 5 & 11 & 11 & 22 & 6 & 15 & $\mathrm{P}<0.001$ \\
\hline
\end{tabular}

Difference in the number of new outcome measures per domain over time. 


\section{Figure legends}

Figure 1. Search results

*sample size unknown in three trials

Figure 2. Number of trials reporting each outcome domain (total 362 trials, 81 outcome domains)

NB: Proportion are expressed in a x10 log scale to display proportion $<1 \%$

Figure 3a. Frequency of outcomes measures (definitions and time points) among trials reporting phosphate (124 trials, 35 outcomes measures)

Abbreviations: Ca, Calcium; $\mathrm{P}$, phosphate

Figure $3 b$. Frequency of outcomes measures (definitions and time points) among trials reporting calcium (109 trials, 35 outcomes measures)

Abbreviations: Ca, Calcium; no.; number; P, phosphate; PTH, parathyroid hormone

Figure 3c. Frequency of outcomes measures (definitions and time points) among trials reporting mortality (74 trials, 48 outcomes measures)

Figure 3d. Frequency of outcomes measures (definitions and time points) among trials reporting cardiovascular diseases (44 trials, 47 outcomes measures)

Figure 3e. Frequency of outcomes measures (definitions and time points) among trials reporting pain (57 trials, 40 outcomes measures)

Figure 3f. Frequency of outcomes measures (definitions and time points) among trials reporting fatigue/energy (34 trials, 18 outcomes measures)

Figure 4. Proportion of trials that reported at least one clinical, patient-reported and surrogate outcome over time.

Difference in the proportion of trials that reported at least one clinical, patient-reported and surrogate outcome over time.

Figure 5. Proportion of trials that specified a primary outcome.

Difference in the categories of primary outcomes over time.

Difference in the proportion of trials that specified a primary outcome over time. 


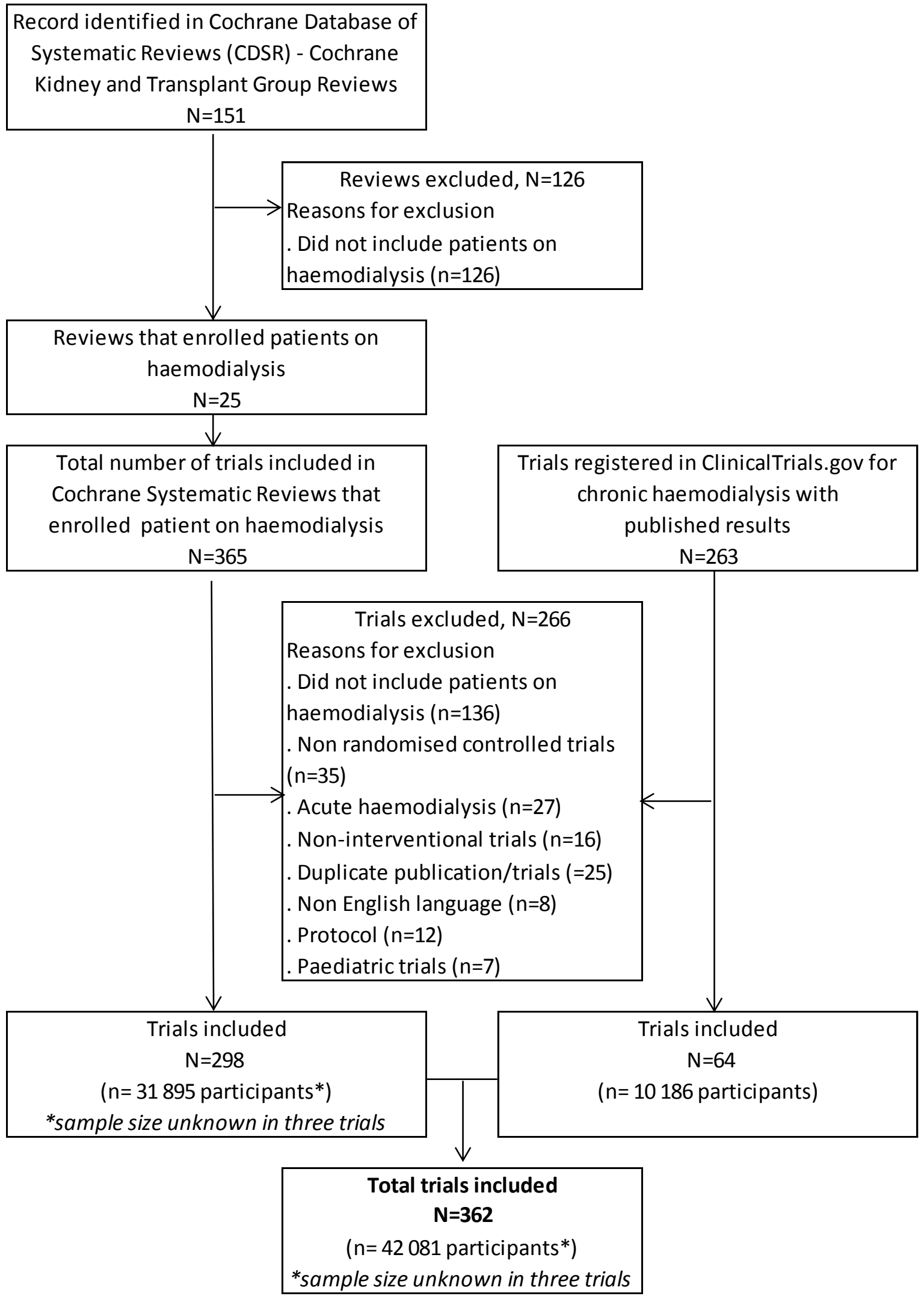




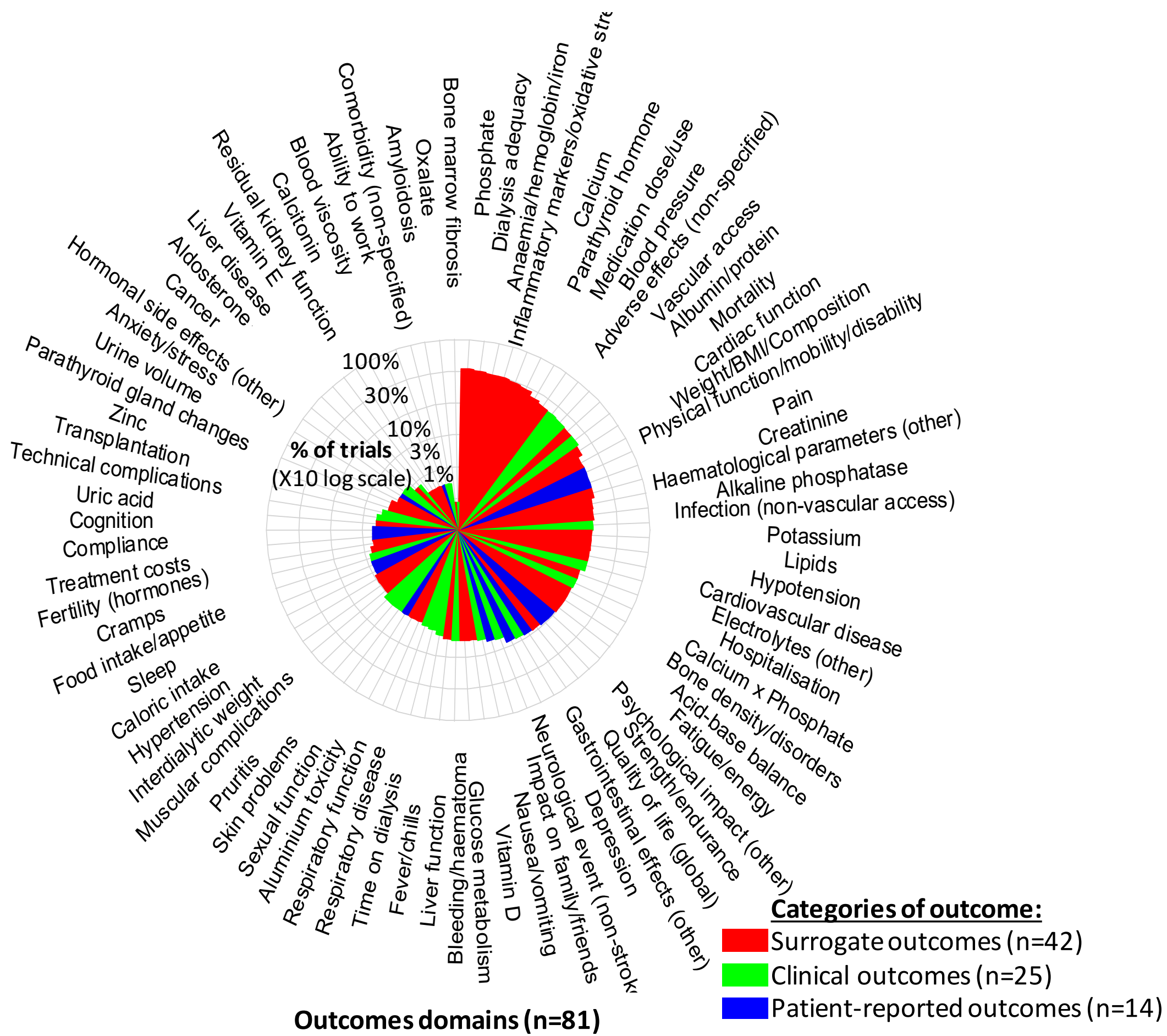




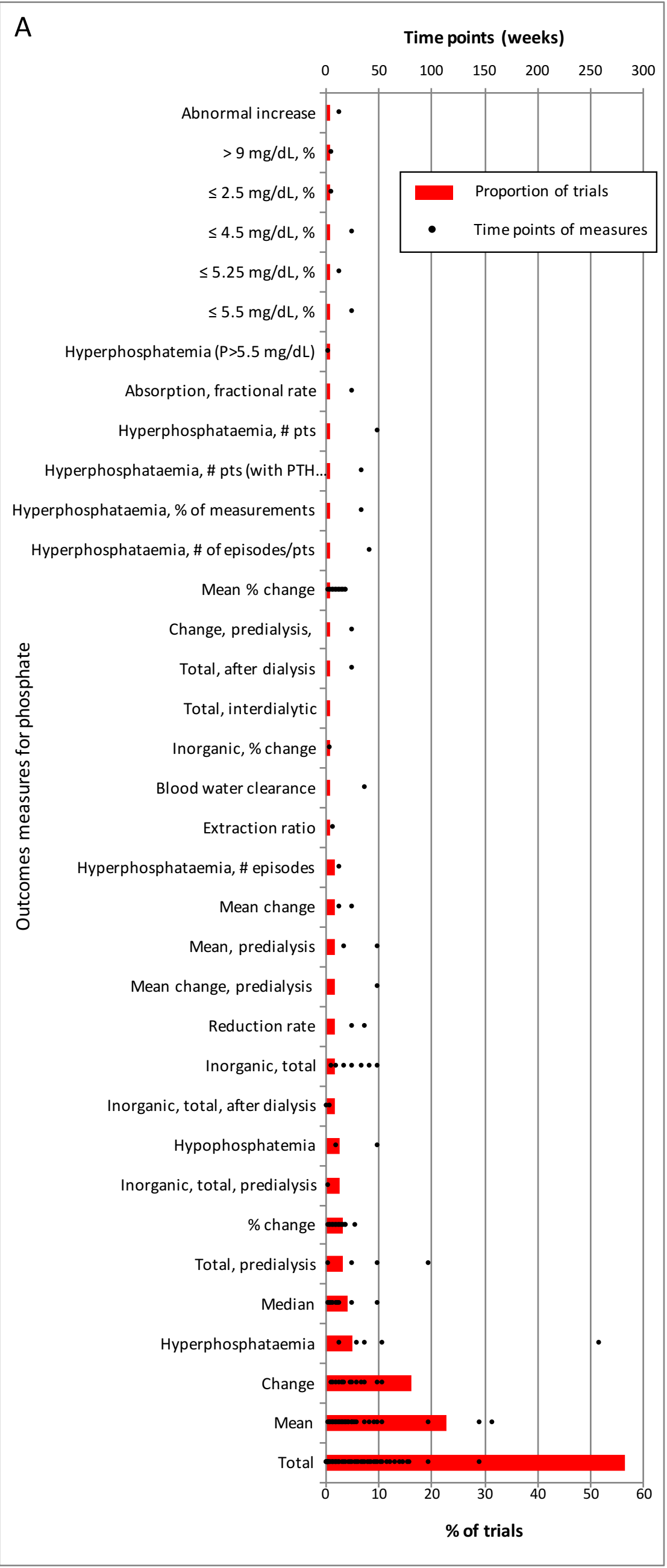


B

Time points (weeks)

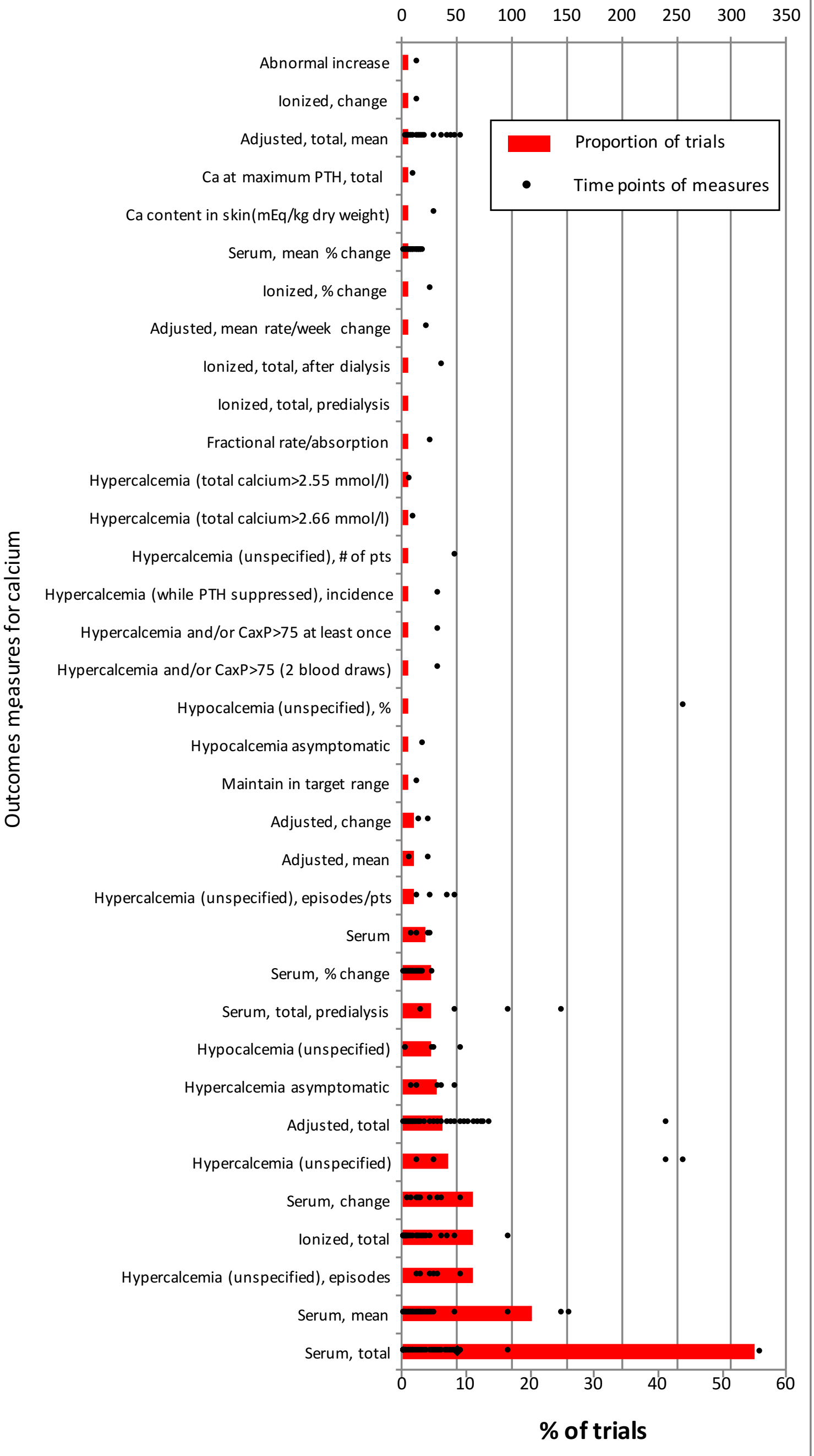




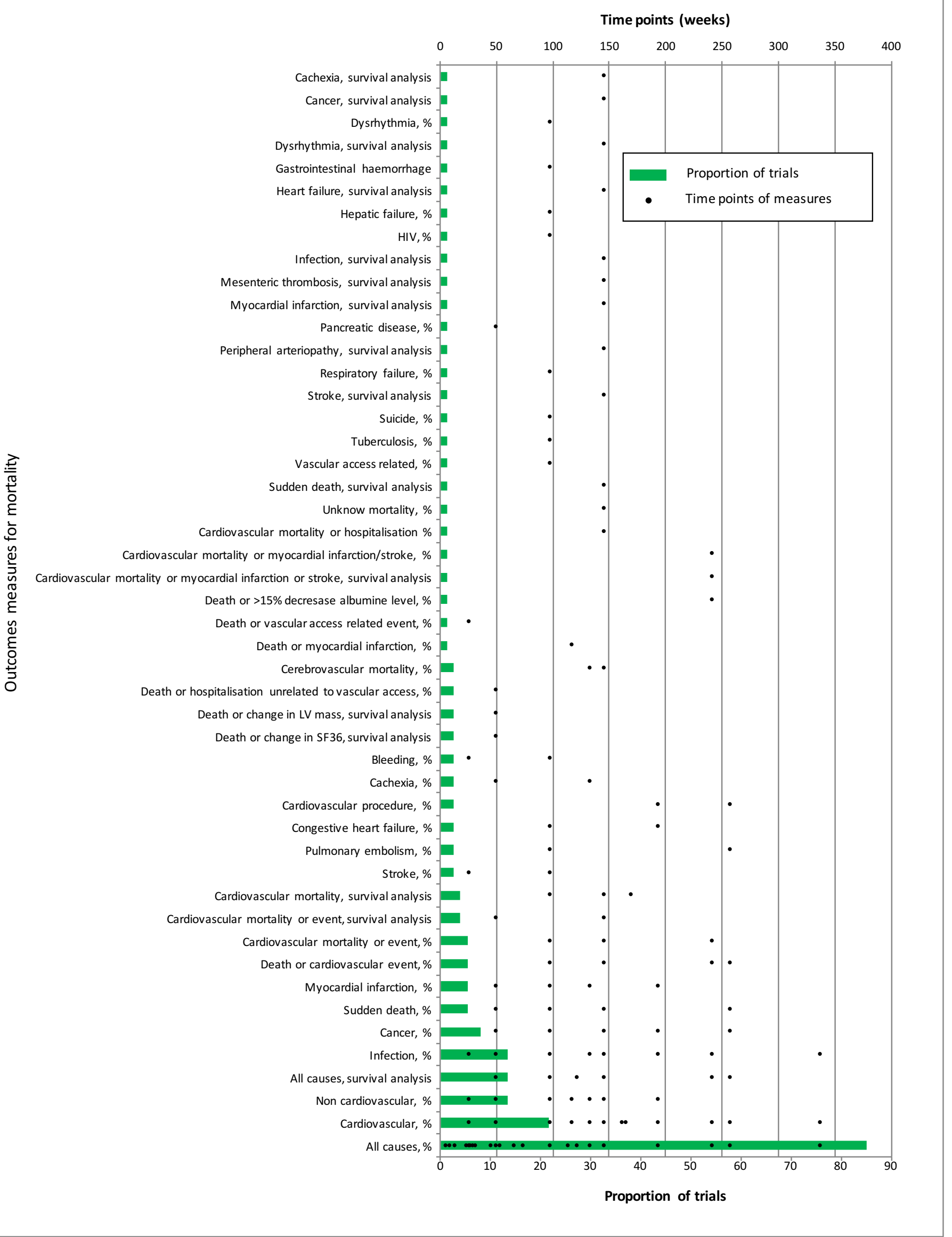


D

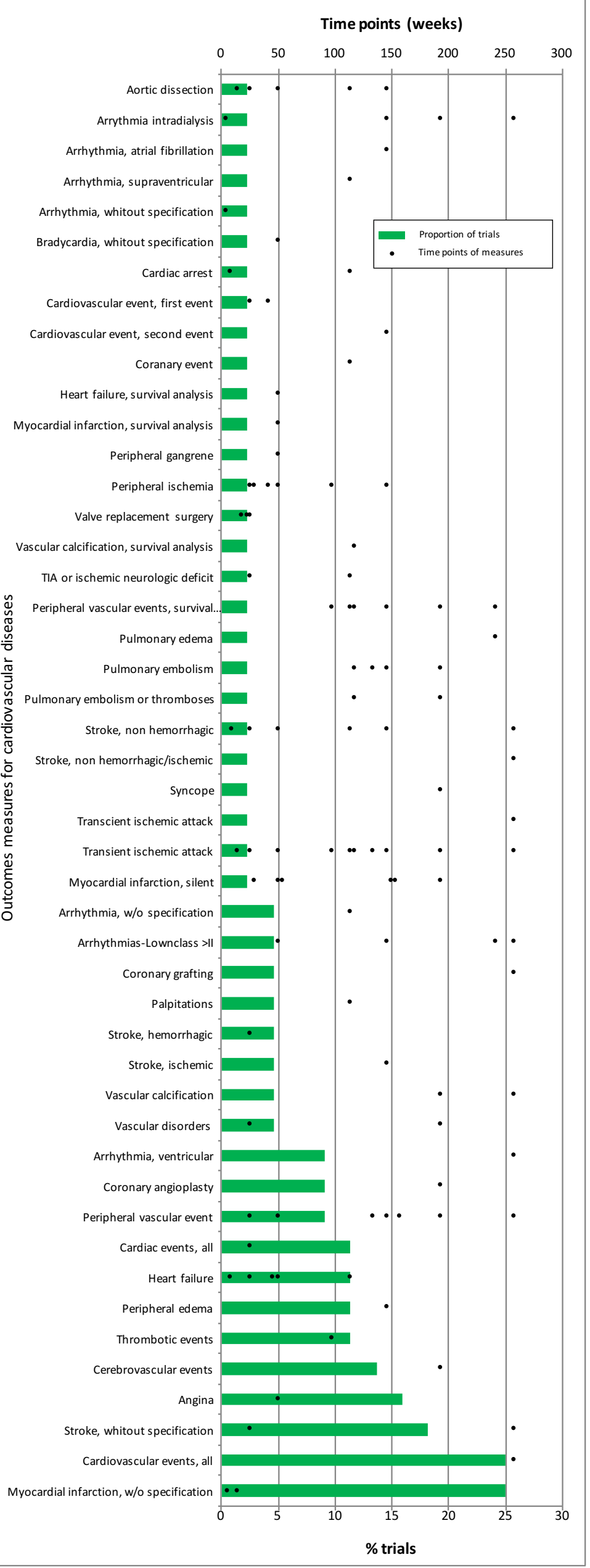




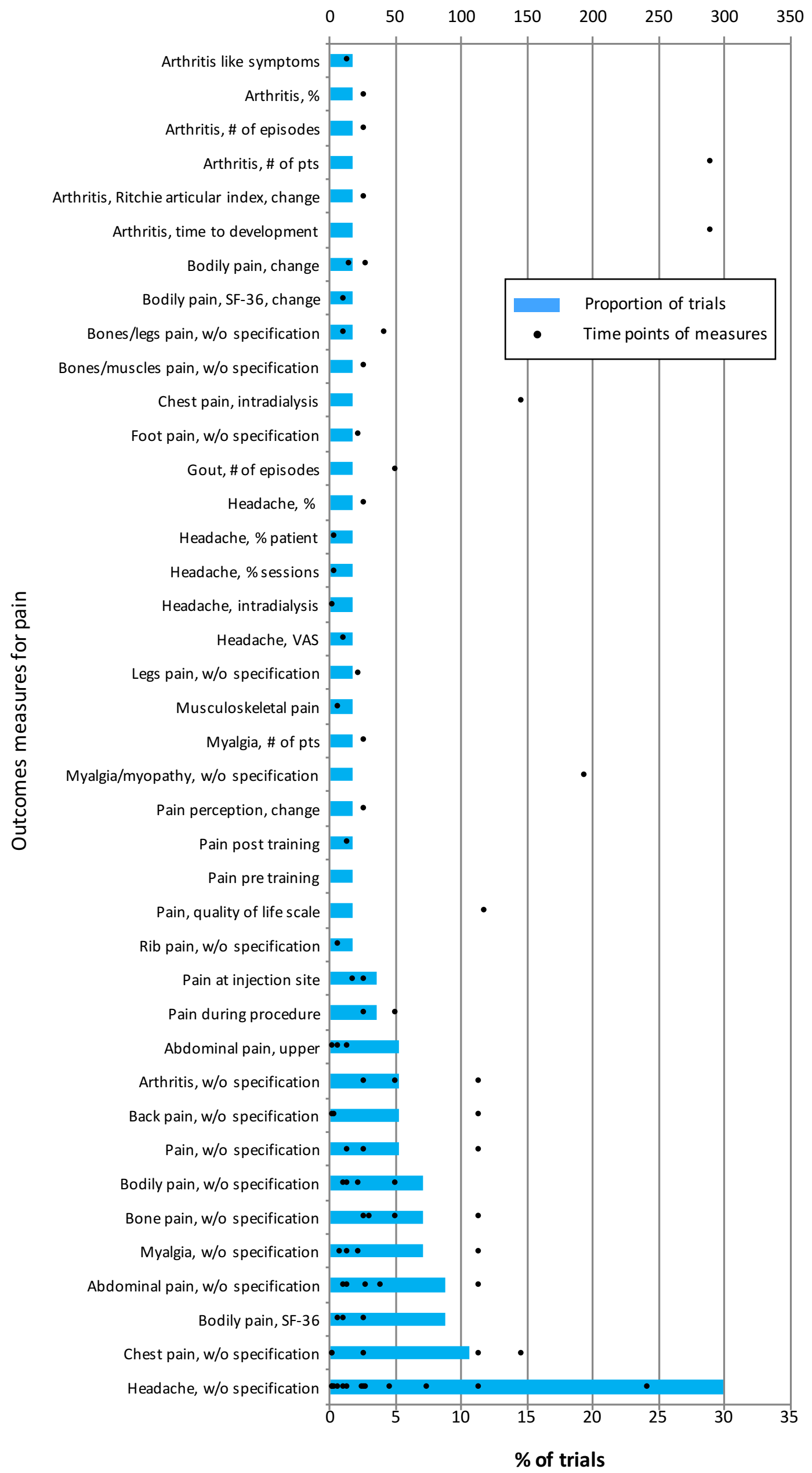




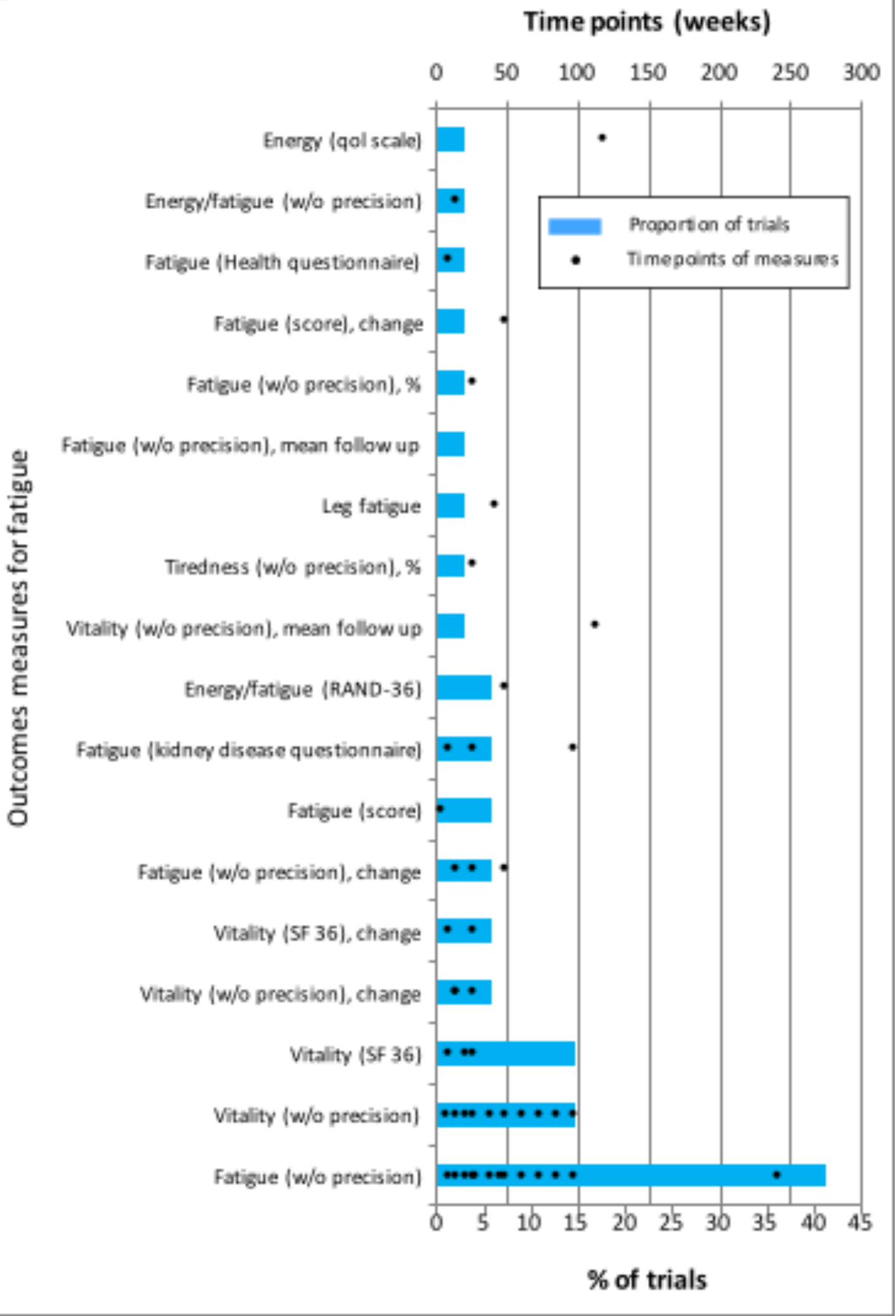




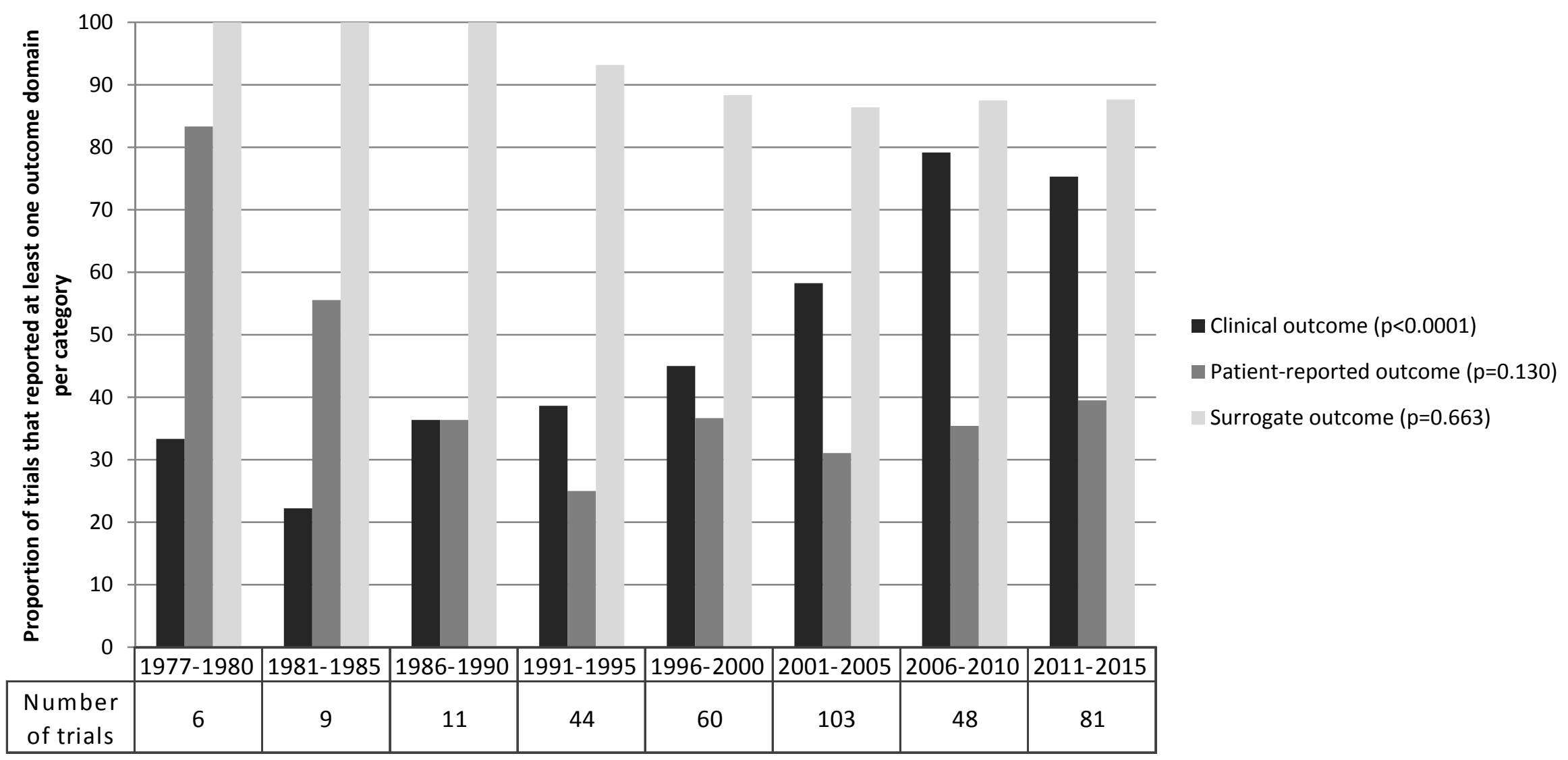

Year of publication 


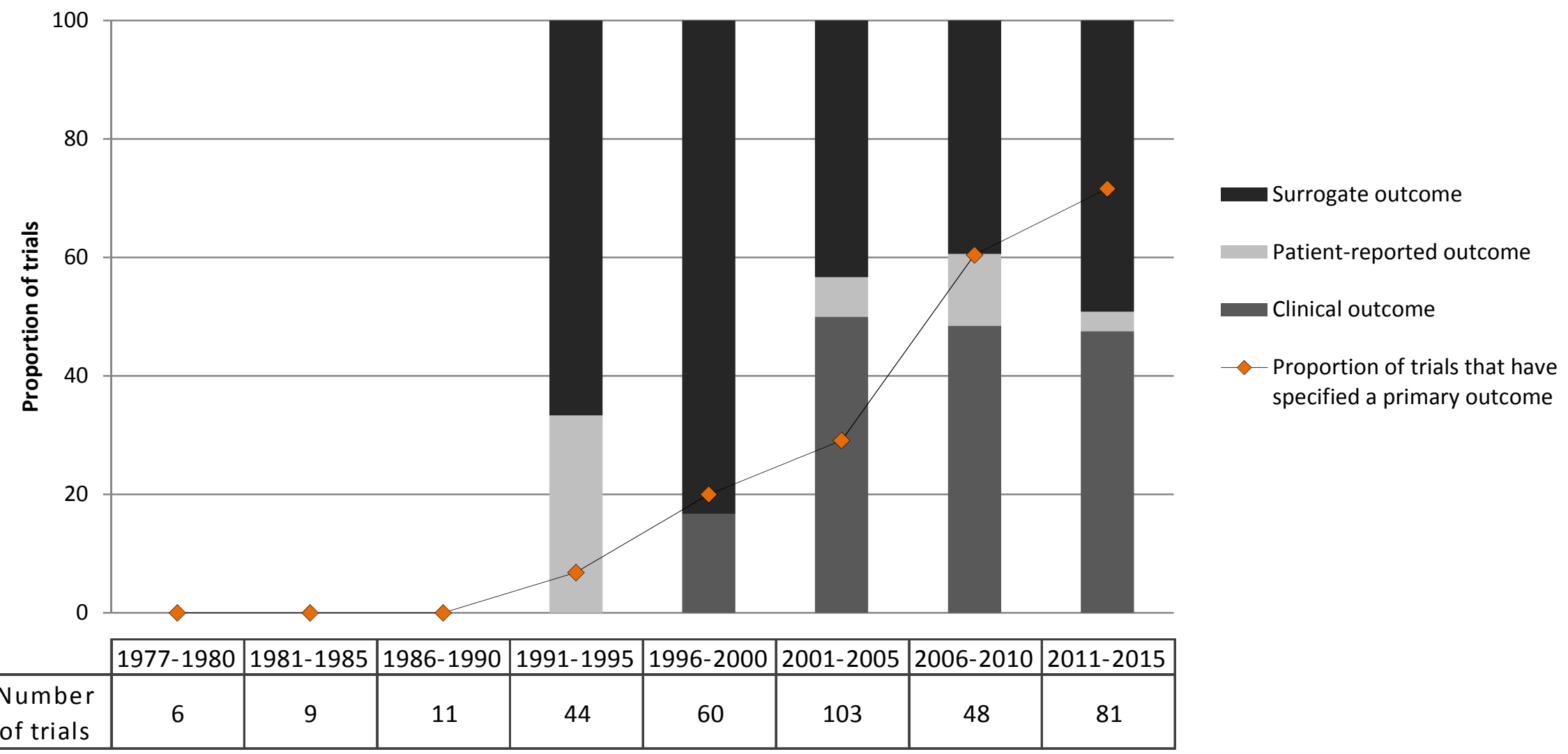

Year of publication 


\section{Supplementary file}

Table S1. Primary outcomes reported in 132 trials

\begin{tabular}{ll}
\hline Domains of primary outcomes (132 trials) & Number of trials n (\%) \\
\hline Vascular access complications & $35(27 \%)$ \\
\hline Mortality & $20(15 \%)$ \\
\hline Parathyroid hormone & $15(11 \%)$ \\
\hline Cardiac function & $12(9 \%)$ \\
\hline Anemia/hemoglobin/iron & $8(6 \%)$ \\
\hline Inflammatory markers/oxidative stress & $8(6 \%)$ \\
\hline Infection (non-vascular access) & $7(5 \%)$ \\
\hline Physical function/mobility/disability & $5(4 \%)$ \\
\hline Adverse effects (non-specified) & $4(3 \%)$ \\
\hline Blood pressure & $4(3 \%)$ \\
\hline Hypotension & $4(3 \%)$ \\
\hline Phosphate & $4(3 \%)$ \\
\hline Strength/endurance & $4(3 \%)$ \\
\hline Albumin/protein & $3(2 \%)$ \\
\hline Hematological parameters (other) & $3(2 \%)$ \\
\hline Weight/BMI/Composition & $3(2 \%)$ \\
\hline Cardiovascular disease & $2(2 \%)$ \\
\hline Pruritus & $2(2 \%)$ \\
\hline Fatigue/energy & $2(2 \%)$ \\
\hline Pain & $2(2 \%)$ \\
\hline Quality of life (global) & $2(2 \%)$ \\
\hline Lipids & $2(2 \%)$ \\
\hline Vitamin D & $2(2 \%)$ \\
\hline Bleeding/hematoma & $1(1 \%)$ \\
\hline Gastrointestinal effects (other) & $1(1 \%)$ \\
\hline Respiratory disease & $1(1 \%)$ \\
\hline Sexual function & $1(1 \%)$ \\
\hline Calcep & $1(1 \%)$ \\
\hline Dialysis adequacy & $1(1 \%)$ \\
\hline Glucose metabolism & $1(1 \%)$ \\
\hline Potassium & $1(1 \%)$ \\
\hline & $1(1 \%)$ \\
\hline Zinc & $1(1 \%)$ \\
\hline & $1(1 \%)$ \\
\hline & $1(1 \%)$ \\
\hline
\end{tabular}


Table S2. Sensitivity analysis of the proportion of trials that reported each outcome domain

\begin{tabular}{|c|c|c|c|c|}
\hline & All trials $(n=362)$ & $\begin{array}{l}\text { Trials } \geq 3 \text { months } \\
(\mathrm{n}=293)\end{array}$ & $\begin{array}{l}\text { Trials }>20 \\
\text { patients }(\mathrm{n}=283)\end{array}$ & $\begin{array}{l}\text { Trials published } \\
\leq 2010(\mathrm{n}=281)\end{array}$ \\
\hline Outcome domain & $\begin{array}{l}\text { Proportion of } \\
\text { trials }(\%)\end{array}$ & $\begin{array}{l}\text { Proportion of } \\
\text { trials }(\%)\end{array}$ & $\begin{array}{l}\text { Proportion of } \\
\text { trials (\%) }\end{array}$ & $\begin{array}{l}\text { Proportion of } \\
\text { trials (\%) }\end{array}$ \\
\hline Ability to work & 0.6 & 0.3 & 0.4 & 0.7 \\
\hline Acid-base balance & 9.9 & 8.5 & 7.1 & 10.3 \\
\hline Adverse effects (non-specified) & 21.8 & 23.2 & 24.4 & 19.2 \\
\hline Albumin/protein & 20.2 & 20.5 & 18.7 & 18.9 \\
\hline Aldosterone & 0.8 & 1.0 & 0.4 & 0.4 \\
\hline Alkaline phosphatase & 13.5 & 15.0 & 14.5 & 15.3 \\
\hline Aluminium toxicity & 3.6 & 4.1 & 3.2 & 4.3 \\
\hline Amyloidosis & 0.6 & 0.3 & NA & 0.7 \\
\hline Anemia/hemoglobin/iron & 31.8 & 33.4 & 30.7 & 31.0 \\
\hline Anxiety/stress & 1.1 & 1.0 & 1.1 & 1.4 \\
\hline Bleeding/hematoma & 5.5 & 5.1 & 6.7 & 4.3 \\
\hline Blood pressure & 22.7 & 23.2 & 20.1 & 22.1 \\
\hline Blood viscosity & 0.6 & 0.7 & 0.4 & 0.7 \\
\hline Bone density/disorders & 9.9 & 11.3 & 9.9 & 10.0 \\
\hline Bone marrow fibrosis & 0.3 & 0.3 & 0.4 & 0.4 \\
\hline Calcitonin & 0.6 & 0.3 & 0.7 & 0.7 \\
\hline Calcium & 30.4 & 31.7 & 29.0 & 29.9 \\
\hline Calcium x Phosphate & 9.9 & 9.6 & 11.0 & 9.3 \\
\hline Caloric intake & 3.0 & 3.4 & 2.5 & 3.2 \\
\hline Cancer & 0.8 & 1.0 & 1.1 & 0.4 \\
\hline Cardiac function & 18.8 & 19.8 & 18.4 & 17.4 \\
\hline Cardiovascular disease & 12.7 & 14.3 & 14.5 & 10.3 \\
\hline Cognition & 2.2 & 2.0 & 2.1 & 0.7 \\
\hline Comorbidity (non-specified) & 0.6 & 0.7 & 0.7 & 0.7 \\
\hline Compliance & 2.2 & 2.4 & 2.8 & 1.8 \\
\hline Cramps & 2.8 & 1.7 & 2.8 & 1.8 \\
\hline Creatinine & 15.5 & 13.3 & 12.4 & 16.7 \\
\hline Depression & 8.3 & 9.2 & 9.5 & 8.5 \\
\hline Dialysis adequacy & 32.6 & 30.0 & 30.4 & 32.0 \\
\hline Electrolytes (other) & 10.2 & 9.6 & 8.5 & 11.0 \\
\hline Fatigue/energy & 9.7 & 10.6 & 10.6 & 9.3 \\
\hline Fertility (hormones) & 2.5 & 2.4 & 0.7 & 3.2 \\
\hline Fever/chills & 4.7 & 4.1 & 4.9 & 4.3 \\
\hline Food intake/appetite & 3.6 & 4.1 & 3.5 & 2.5 \\
\hline Gastrointestinal effects (other) & 8.8 & 7.8 & 9.9 & 4.6 \\
\hline Glucose metabolism & 5.5 & 5.5 & 4.9 & 3.9 \\
\hline $\begin{array}{l}\text { Hematological parameters } \\
\text { (other) }\end{array}$ & 13.8 & 11.6 & 13.1 & 11.4 \\
\hline Hormonal side effects (other) & 1.1 & 1.4 & 1.1 & 0.4 \\
\hline Hospitalization & 10.2 & 12.3 & 11.7 & 8.5 \\
\hline Hypertension & 3.0 & 3.4 & 3.5 & 2.5 \\
\hline Hypotension & 11.9 & 11.9 & 11.3 & 10.0 \\
\hline Impact on family/friends & 6.4 & 6.5 & 6.4 & 6.4 \\
\hline Infection (non-vascular access) & 13.0 & 15.4 & 15.2 & 11.0 \\
\hline $\begin{array}{l}\text { Inflammatory markers/oxidative } \\
\text { stress }\end{array}$ & 31.5 & 28.0 & 27.6 & 32.0 \\
\hline Interdialytic weight & 3.0 & 3.4 & 2.5 & 2.8 \\
\hline Lipids & 12.4 & 11.6 & 13.1 & 12.5 \\
\hline Liver disease & 0.8 & 0.7 & 1.1 & 0.7 \\
\hline Liver function & 5.2 & 5.5 & 5.3 & 6.4 \\
\hline Medication dose / use & 24.3 & 27.3 & 25.1 & 26.3 \\
\hline
\end{tabular}




\begin{tabular}{|c|c|c|c|c|}
\hline Mortality & 20.2 & 24.2 & 24.4 & 16.7 \\
\hline Muscular complications & 3.6 & 4.1 & 3.9 & 3.6 \\
\hline Nausea/vomiting & 5.8 & 5.8 & 6.7 & 4.3 \\
\hline Neurological event (non-stroke) & 6.6 & 7.2 & 6.0 & 4.6 \\
\hline Oxalate & 0.3 & 0.3 & 0.4 & 0.4 \\
\hline Pain & 15.7 & 14.3 & 16.3 & 13.2 \\
\hline Parathyroid gland changes & 1.4 & 1.4 & 0.7 & 1.1 \\
\hline Parathyroid hormone & 28.7 & 30.7 & 29.3 & 28.1 \\
\hline Phosphate & 34.5 & 35.2 & 33.9 & 33.8 \\
\hline $\begin{array}{l}\text { Physical } \\
\text { function/mobility/disability }\end{array}$ & 15.7 & 17.7 & 17.0 & 16.7 \\
\hline Potassium & 12.4 & 12.3 & 11.3 & 11.0 \\
\hline Pruritis & 3.6 & 2.0 & 3.9 & 3.2 \\
\hline Psychological impact (other) & 9.4 & 9.9 & 10.6 & 9.6 \\
\hline Quality of life (global) & 8.8 & 9.6 & 9.9 & 9.3 \\
\hline Residual kidney function & 0.6 & 0.7 & 0.4 & 0.7 \\
\hline Respiratory disease & 3.6 & 3.8 & 4.2 & 2.1 \\
\hline Respiratory function & 3.6 & 4.1 & 3.5 & 4.3 \\
\hline Sexual function & 3.6 & 3.1 & 1.8 & 4.6 \\
\hline Skin problems & 3.6 & 3.8 & 4.2 & 2.5 \\
\hline Sleep & 2.8 & 2.4 & 2.8 & 1.4 \\
\hline Strength/endurance & 9.1 & 11.3 & 10.6 & 11.4 \\
\hline Technical complications & 1.7 & 2.0 & 1.8 & 2.1 \\
\hline Time on dialysis & 4.1 & 2.7 & 4.6 & 3.2 \\
\hline Transplantation & 1.7 & 2.0 & 2.1 & 2.1 \\
\hline Treatment costs & 2.2 & 2.4 & 2.1 & 2.8 \\
\hline Uric acid & 1.9 & 2.0 & 1.8 & 1.8 \\
\hline Urine volumne & 1.1 & 1.0 & 0.7 & 0.7 \\
\hline Vascular access complications & 22.9 & 24.6 & 26.9 & 19.2 \\
\hline Vitamin D & 5.8 & 6.5 & 5.7 & 3.9 \\
\hline Vitamin E & 0.6 & 0.3 & 0.7 & 0.7 \\
\hline Weight/BMI/Composition & 15.5 & 16.0 & 15.5 & 16.0 \\
\hline Zinc & 1.4 & 1.4 & 0.4 & 1.4 \\
\hline
\end{tabular}


Figure S1. Number of outcome measures reported in clinical trials over 5-year intervals.

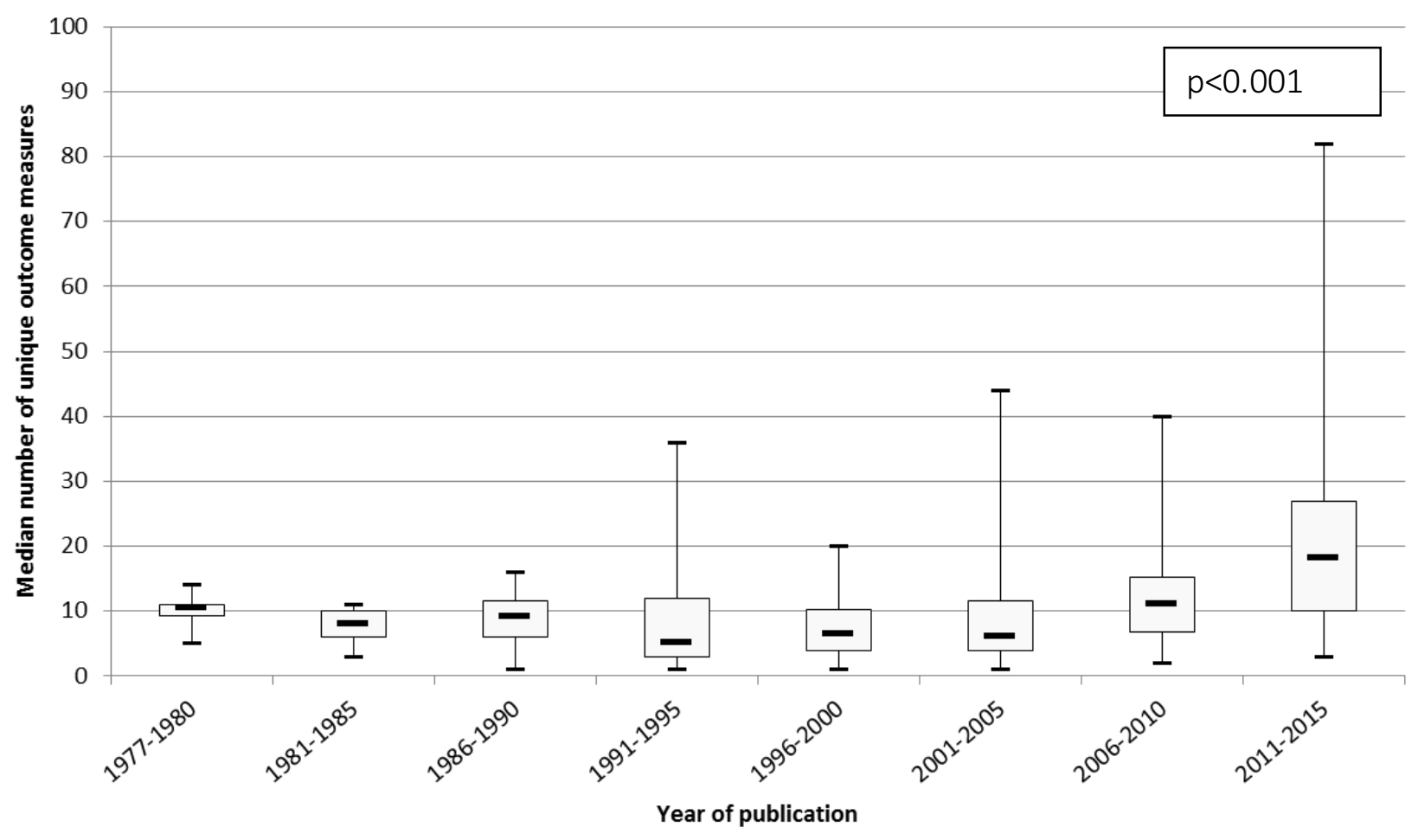

Difference in number of outcome measures per trial over time. Each boxplot is the number of outcomes in trials in the time period. the line in the boxplot is the median number. 
Figure S2. Frequency of outcomes measures (definitions and time points) among trials reporting quality of life (33 trials. 37 outcomes measures)

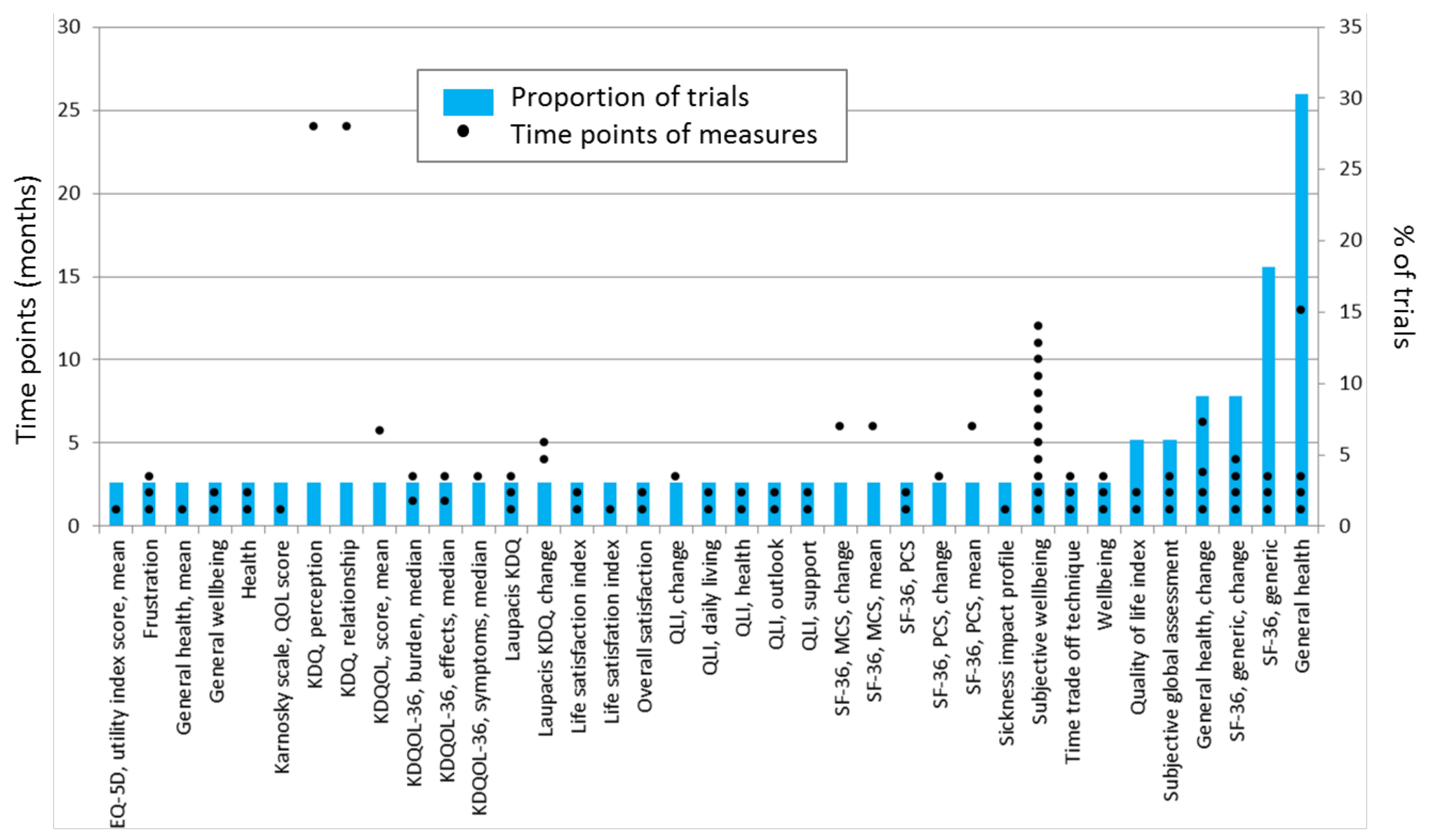

Outcome measures for quality of life 


\section{Search terms:}

\section{Cochrane library:}

“dialysis" [Title. abstract. keywords]

OR "haemodialysis" [Title. abstract. keywords]

OR "hemodialysis" [Title. abstract. keywords]

ClinicalTrials.gov:

Other terms: Dialysis

Study Type: Interventional studies

Study results: Studies with results 